\title{
DAS AVALIAÇÕES OBJETIVAS AOS DIÁRIOS REFLEXIVOS ON- LINE: EXPERIÊNCIAS DE UMA PROFESSORA COM A AVALIAÇÃO DA APRENDIZAGEM
}

\author{
FROM OBJECTIVE EVALUATIONS TO ONLINE REFLECTIVE DIARIES: EXPERIENCES \\ OF A TEACHER WITH THE LEARNING ASSESSMENT
}
DE LAS EVALUACIONES OBJETIVAS A LOS DIARIOS REFLEXIVOS ON-LINE: EXPERI- ENCIAS DE UNA PROFESORA CON LA EVALUACIÓN DEL APRENDIZAJE

Claudia Almeida Rodrigues Murta

E-mail: claudia.murta@uftm.edu.br

Universidade Federal do Triângulo Mineiro - UFTM

\begin{abstract}
RESUMO
A avaliação da aprendizagem é um tema fundamental para a educação que necessita ser entendido para que haja melhoria na aprendizagem dos alunos, visto que a avaliação deve estar a serviço daquele que aprende. Experiências bem sucedidas com a avaliação da aprendizagem devem ser compartilhadas para que novos olhares sejam lançados para essa ação pedagógica. O objetivo desse trabalho é discutir a questão da avaliação da aprendizagem na perspectiva de uma professora, descrevendo suas experiências avaliativas e a transformação de suas concepções de avaliação ao longo de sua atuação nos diversos contextos de ensino, inclusive o on-line.
\end{abstract}

PALAVRAS-CHAVE: Avaliação da aprendizagem. Concepções de avaliação. Contextos de aprendizagem.

\section{ABSTRACT}

The evaluation of learning is a key theme for education that needs to be understood so there is improvement in student learning, since the assessment must be at the service of who is learning. Successful experiences with the evaluation of learning should be shared for new views to be laid for this pedagogical action The aim of this paper is to discuss the issue of assessment of learning from the perspective of a teacher, describing her evaluation experiences and the transformation of its evaluation concepts throughout its operations in different educational contexts, including online.

KEYWORDS: Evaluation of learning. Assessment concepts. Learning contexts

\section{RESUMEN}

La evaluación del aprendizaje es un tema fundamental para la educación, que necesita ser entendida para que ocurra una mejora en la formación de los alumnos, ya que la evaluación debe estar al servicio de aquel que aprende. Experiencias satisfactorias con la evaluación del aprendizaje deben ser compartidas para que nuevos puntos de vista sean direccionados a esta acción pedagógica. El objetivo de este trabajo es discutir la cuestión de la evaluación del aprendizaje en la perspectiva de una profesora, describiendo sus experiencias analíticas y la transformación de sus conceptos de evaluación a lo largo de su actuación en los diversos contextos educativos, inclusive el on-line.

PALABRAS-CLAVE: Evaluación del aprendizaje. Concepciones de evaluación. Contextos de aprendizaje. 


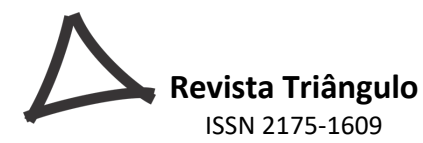

ISSN 2175-1609

\section{INTRODUÇÃO}

A avaliação é um processo natural na vida cotidiana. Avaliamos nosso comportamento diante das situações, avaliamos todas as atividades que desenvolvemos, buscando um melhor desempenho, uma melhor estratégia de sobrevivência. Avaliamos para saber nossa real condição para agirmos no sentido de aperfeiçoar, de melhorar o estado em que nos encontramos. Avaliamos para compreender, para estimar, para apreciar, para conhecer o valor de algo. Essa é a acepção geral da palavra avaliação.

A avaliação, no entanto, no meio educacional adquiriu significados arbitrários, autoritários e excludentes ao longo da história escolar, tratando-a apenas como um mecanismo de verificação da aprendizagem do aluno e de classificação de seu desempenho, tornando-se um instrumento muitas vezes contrário à melhoria de sua condição e também de sua exclusão do sistema escolar.

Segundo Luckesi (2005b), o que a escola vem praticando sistematicamente não é avaliação da aprendizagem, embora leve o nome, e sim exame da aprendizagem, visto que o exame é uma prática pontual, que opera com desempenho final, que classifica o aluno em aprovado ou reprovado e que pode selecionar ou excluir o aluno da escola.

Os exames, da forma como conceitua Luckesi (2005b), muitas vezes são necessários em casos como nos sistemas massivos de avaliação, ou seja, em exames de larga escala, como vestibulares, ENEM, entre outros, com os quais nosso sistema educacional tem que operar, como uma forma de verificação da aprendizagem pontual para a seleção e classificação dos alunos para um número limitado de vagas em nossas universidades. Ou ainda para "medir" o desempenho dos alunos em exames como SAEB, Prova Brasil, ENADE, por exemplo, classificando alunos, escolas e até países em níveis de proficiência em determinadas habilidades e competências.

O que torna o exame algo negativo, a meu ver, é sua prática única e exclusiva, sem uma tomada de decisão e intervenção na aprendizagem mediante seus resultados. Essa prática pode ter gerado uma gama de problemas, como os altos índices de reprovação e baixos níveis de letramento do aluno, evidenciados nas escolas brasileiras. Se o processo avaliativo terminar com o exame, nada sendo feito com seu resultado, nenhum tipo de intervenção, a pura e simples constatação do nível de aprendizagem do aluno, não se estará respeitando a dinâmica do 


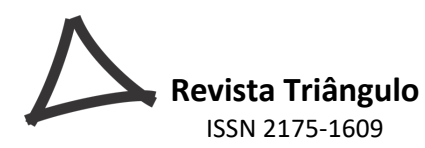

processo de aprender, que é contínuo. A avaliação, assim, assume um caráter estático e perde sua função básica que é diagnosticar para uma tomada de decisão.

Se com a constatação do exame nada for feito para a melhoria da qualidade da aprendizagem do aluno, retomando aquilo que ele demonstrou não ter aprendido, de nada adianta essa verificação.

Acredito que o exame por si só não é bom nem ruim, é o que se faz com o seu resultado que o tornará um instrumento avaliativo formativo ou excludente. Nesse ponto, não concordo com o autor Luckesi, que atribui ao exame esse caráter eminentemente negativo.

Contudo, pretendo continuar a diferenciar os termos exame e avaliação, conforme preconiza Luckesi (2005a), e discutir esse tema tomando como conceito de avaliação da aprendizagem, uma acepção educativa e humanizadora do termo, de acordo com Sant'Anna (1998), como sendo "um processo pelo qual se procura identificar, aferir, investigar e analisar as modificações do comportamento e rendimento do aluno, do educador, do sistema, confirmando se a construção do conhecimento se processou, seja este teórico (mental) ou prático” (SANT’ANNA, 1998, p.29, 30).

Minha intenção neste texto é abordar a avaliação da aprendizagem em sua acepção formativa, emancipadora, como subsídio teórico para narrar minha prática enquanto professora e avaliadora da aprendizagem de meus alunos e as transformações que essa prática sofreu e sofre a cada turma, a cada nova jornada de trabalho e também em outro ambiente de aprendizagem, o on-line. Minha intenção é chamar a atenção de colegas e demais agentes educacionais sobre esse tema fundamental para o desenvolvimento do aluno e da própria escola. Será que poderíamos dizer que a escola não muda porque não se muda a avaliação?

\section{REFERENCIAL TEÓRICO}

Luckesi (1996, p.33) definiu a “(...) avaliação como um juízo de qualidade sobre dados relevantes para uma tomada de decisões”. A tomada de decisões é a ação precípua da avaliação, sua principal função é diagnosticar o estágio em que se encontra a aprendizagem do aluno em relação a novos conhecimentos, ao desenvolvimento da autonomia e de competências. Luckesi 
(2005a) evidencia como principal papel da avaliação, o de diagnosticar a situação da aprendizagem subsidiando a tomada de decisão para a melhoria do desempenho do aluno. E ainda, complementa Luckesi em texto mais recente, "a avaliação deverá verificar a aprendizagem não a partir de mínimos possíveis, mas sim a partir dos mínimos necessários” (LUCKESI, 2014, p. 13), para que o aluno possa participar democraticamente da vida social. Remião (2007) explica que o que caracteriza a avaliação diagnóstica, em se tratando de educação, é a intenção prévia do professor de providenciar ações reorientadoras da prática educativa.

Nesse sentido, a avaliação da aprendizagem é um ato de ajuda, de acolhimento, como bem lembra Luckesi (2005b), é um ato amoroso. O autor menciona que o professor, nessa tarefa, deve ser solidário com o aluno e explica que

\begin{abstract}
ser solidário com o educando no processo de avaliação significa acolhê-lo em sua situação específica, ou seja, como é e como está nesse momento, para, a seguir, se necessário, confrontá-lo e reorientá-lo amorosamente, para que possa construir-se a si mesmo como sujeito que é (ser), o que significa construir-se como sujeito que aprende (aquisição de conhecimentos), como sujeito que age (o fazer) e como sujeito que vive com outros (tolerância, convivência, respeito). Confrontar, aqui, não significa desqualificar ou antagonizar com o educando, mas tão somente, amorosamente, auxiliá-lo a encontrar a melhor solução para a situação que está vivendo, seja ela cognitiva, afetiva ou espiritual (LUCKESI, s.d.)
\end{abstract}

Tyler (1979) definiu avaliação como sendo o processo de determinar em que medida os objetivos educacionais estão sendo atingidos e como as mudanças de comportamento estão ocorrendo. Essa concepção, muito difundida na Educação, confunde avaliação com medida e visa apenas ao produto da avaliação.

A abordagem tecnicista considera que a aprendizagem pode ser quantificada e, portanto, medida. Tais estudos fundamentam a chamada "Pedagogia Tecnicista", conforme explica Caldeira (1997):

A Pedagogia Tecnicista busca sua concepção de aprendizagem na psicologia comportamental. Esta sempre buscou adquirir o "status" de ciência, libertando-se da introspecção e fundamentando-se na lógica científica dominante que lhe garantisse a objetividade das ciências da natureza. Seu principal foco de preocupação são as mudanças comportamentais que possam ser cientificamente observadas, portanto, quantificadas. (p. 53) 


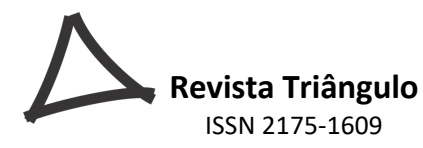

Esses modelos de avaliação, baseados numa pedagogia científica e tecnicista, são a base utilizada tradicionalmente nas escolas brasileiras para avaliar o desempenho dos alunos e no início de minha atuação docente eram as bases de minhas avaliações, pois acreditando que a única maneira "segura" de avaliar meus alunos seria por meio de testes, especialmente os de múltipla escolha, pois achava que eles transpareciam a objetividade e a imparcialidade requeridas no processo de avaliar. Portanto, acreditava que a forma mais "autêntica" de se avaliar seria por meio da prova, pois ela mediria o grau de conhecimentos dos alunos.

Mas, o que seria medir? Hadji (2001, p. 7) afirma que medir significa atribuir um número a um acontecimento ou a um objeto, de acordo com uma regra logicamente aceitável. Segundo esse autor, a ideia de que a avaliação é uma medida dos desempenhos dos alunos é uma crença de professores e, frequentemente, de alunos. E de difícil superação devido ao fato de ser uma prática que se desenvolve há muito tempo e à confiabilidade dada à quantificação numérica dos fenômenos creditada pela cientificidade da Pedagogia Tecnicista.

Gatti (2003) faz uma afirmação que traduz a confusão que se faz entre avaliar e medir, que esclarece substancialmente a questão

É preciso ter presente, também, que medir é diferente de avaliar. Ao medirmos um fenômeno por intermédio de uma escala, de provas, de testes, de instrumentos calibrados ou por uma classificação ou categorização, apenas estamos levantando dados sobre uma grandeza do fenômeno. (...) Mas, a partir das medidas, para termos uma avaliação é preciso que se construa o significado dessas grandezas em relação ao que está sendo analisado quando considerado como um todo, em suas relações com outros fenômenos, suas características historicamente consideradas, o contexto de sua manifestação, dentro dos objetivos e metas definidos para o processo de avaliação, considerando os valores sociais envolvidos. (GATTI, 2003, p. 110)

Hadji (2001) afirma que avaliar não é medir, avaliar é confrontar em processo de negociação. É impossível uma reforma do instrumento avaliador, a partir da ideia da objetividade neutra. Não existe neutralidade quando se trata de um sujeito, no caso o professor, é impossível avaliar de forma imparcial seus alunos, visto que o professor enquanto sujeito é 


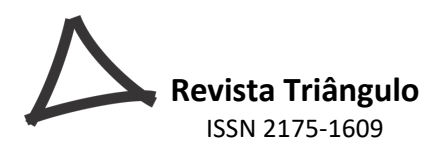

ISSN 2175-1609

atravessado pelas forças sociais e ideológicas que o movem, é inútil tentar tornar a avaliação tão objetiva quanto uma medida.

De acordo com Domingos Fernandes (2006), mudar e melhorar práticas de avaliação formativa implica que o seu significado seja claro para os professores, devido ao fato de que são muito fortes e imbricadas as suas relações com os processos de ensino e de aprendizagem. O mesmo autor argumenta que a avaliação formativa, tal como era entendida nos anos 60 e 70 do século XX, pouco tem a ver com a avaliação formativa dos dias de hoje. Segundo Fernandes (2006, p.22-23),

\begin{abstract}
No primeiro caso, estamos perante uma visão mais restritiva, centrada em objetivos comportamentais e nos resultados obtidos pelos alunos, pouco interativa e, por isso, normalmente realizada após um dado período de ensino e de aprendizagem. No segundo caso, estamos perante uma avaliação bem mais complexa e, num certo sentido, mais sofisticada, ou mais rica, do ponto de vista teórico. Trata-se de uma avaliação interativa, centrada nos processos cognitivos dos alunos e associada aos processos de feedback, de regulação, de auto-avaliação e de auto-regulação das aprendizagens.
\end{abstract}

Por isso, é preciso que se delineie teoricamente o que seja avaliação formativa para alinhar o que se entende e o que se pratica desse tipo de avaliação. Segundo Fernandes (2006), a primeira acepção de avaliação formativa está mais alinhada ao que Luckesi (2005b) denomina de exame ou o que ele mesmo denomina de sumativa, para nós brasileiros, somativa. Fernandes (2006, p. 23) atesta que este tipo de avaliação formativa "pode ocorrer após o desenvolvimento de um domínio do currículo num dado período de tempo, imediatamente antes de um momento de avaliação sumativa formal, sob a forma das chamadas revisões da matéria dada ou de um teste formativo".

Lima e Grillo (2010) ponderam que a configuração do sistema de ensino exige que se trate da avaliação de produto, aquela que tem uma função classificatória, que objetiva o julgamento do rendimento do aluno ao final de uma determinada etapa - unidade, semestre, ano ou curso -, segundo o aproveitamento expresso em graus, notas ou conceitos. Segundo esses 


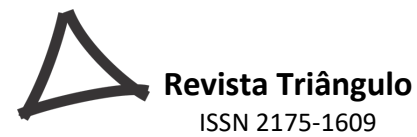

autores, na avaliação de produto também ocorre a identificação de sucessos e de fragilidades na aprendizagem do aluno, não só na avaliação do processo esses elementos podem ser detectados. Os autores $(2010$, p. 28$)$ afirmam que o que confunde o entendimento das duas modalidades de avaliação (de produto e de processo) é que há casos em que professores, mesmo dizendo-se favoráveis à avaliação de processo, omitem a comunicação dos resultados ao aluno em tempo hábil, impedindo que ele participe da reorientação de sua aprendizagem, restringindose ao conhecimento de um resultado final obtido pela média de várias provas. Outros limitamse à avaliação de produto e realizam uma única prova final, o que impede que o aluno conheça sua situação ao longo do processo.

Acredito que enquanto nosso sistema educacional não mudar seus paradigmas fundantes, a avaliação formativa, em sua concepção humanizadora e emancipatória será uma "utopia promissora", como argumenta Hadji (2001). A avaliação que regule a aprendizagem, que almeje o progresso do aluno, que veja no erro uma fonte de informação para a análise, tanto do professor quanto do próprio aluno, para se chegar à aprendizagem, ainda está longe de ser uma realidade na maioria das escolas brasileiras.

Esse tipo de avaliação, como a mencionada por Hadji (2001), está de acordo com a segunda concepção que Fernandes (2006, p. 24) afirma ter sido amplamente utilizada

\footnotetext{
partir dos anos 90 do século XX, como uma espécie de guarda-chuva sob o qual se abriga todo e qualquer processo de avaliação destinado a regular e a melhorar as aprendizagens, focado nos processos, mas sem ignorar os produtos, participado, transparente, que não seja essencialmente baseado em testes de papel e lápis e integrado nos processos de ensino e de aprendizagem.
}

Com relação à avaliação formativa, Hadji (2001, p. 19) sustenta que sua função principal é a de contribuir para uma boa regulação da atividade de ensino, de levantar informações úteis à regulação do processo de ensino e aprendizagem. Todavia, ele lembra que uma avaliação não precisa conformar-se a nenhum padrão metodológico para ser formativa. O que tornará um instrumento de avaliação formativo será o que se fará com o seu resultado, a comunicação ao 


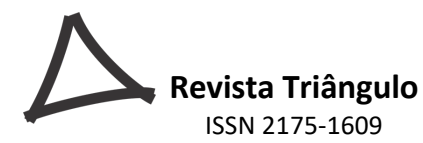

ISSN 2175-1609

aluno de seu desempenho, a retomada e intervenção nos pontos falhos da aprendizagem e novo diagnóstico analisando se houve sucesso no processo. Ou seja, o que torna a avaliação formativa é estar a serviço do processo de desenvolvimento daquele que aprende, que deve informar aos agentes desse processo, professor e aluno, o andamento do processo, as dificuldades e efeitos do trabalho pedagógico e ainda corrigir a ação, modificando metodologias e atitudes. De acordo com Hadji (2001), na avaliação com intenção formativa, o papel do professor avaliador é:

1) Desencadear comportamentos a observar

2) Interpretar os comportamentos observados

3) Comunicar os resultados das análises

4) Remediar os erros e as dificuldades analisadas.

Luckesi (2001), em relação às funções da avaliação, argumenta que sua função ontológica é a de diagnosticar. O diagnóstico representa a base para uma coerente tomada de decisão, visto que se trata do meio de encaminhar os atos subsequentes, na perspectiva de uma situação positiva em relação aos resultados almejados.

O reconhecimento da avaliação formativa, segundo Hadji (2001), está associado à variabilidade das práticas do professor, mas que ninguém pode estar certo de que está fazendo avaliação formativa, por isso o autor denomina a avaliação formativa como uma possibilidade utópica e a única forma de se constatar a avaliação formativa é a relação de ajuda que se estabelece entre professor e aluno.

Como discorri até o momento, a avaliação da aprendizagem é um tema caro à Educação e que desperta interesse em áreas que estão diretamente ligadas à questão do ensino, como é o caso da Linguística Aplicada (LA). Nos últimos anos, a LA tem fomentado discussões nos mais diferentes campos, investigando questões como o bilinguismo e multilinguismo, a análise do discurso, a tradução, a política e planificação da linguagem, a metodologia de pesquisa, a estilística, a avaliação, a literatura, a retórica, o letramento, problemas de ordem forense e de saúde, e outras áreas em que decisões relacionadas com a linguagem precisam ser tomadas. 


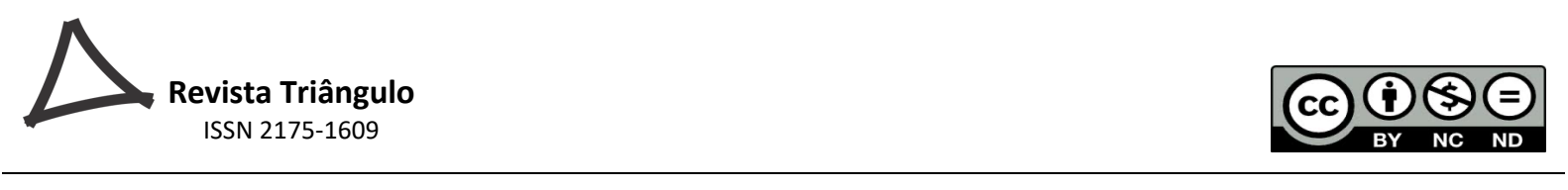

A LA apresenta-se, na atualidade, como uma promissora área de investigação em função de seu caráter interdisciplinar, transdisciplinar e, segundo palavras de Moita Lopes (2006), (in)disciplinar. Isso significa que a LA não trabalha com limites rígidos, ela se constitui híbrida e heterogênea, com foco em outras áreas do conhecimento socialmente construído e utiliza diferenciados modos de analisar os dados de pesquisa e que, inclusive, transgridem radicalmente os limites disciplinares. A LA coloca em diálogo áreas díspares, levando o pesquisador a assumir uma postura de abertura de espírito, de tolerância, disposição para viver com a incerteza e o risco. Por isso, acho importante ressaltar que a avaliação da aprendizagem faz parte de nossa agenda de estudos como linguistas aplicados e, pelo caráter transfronteiriço da LA, subsídios teóricos de outras áreas podem sustentar as investigações que desenvolvemos, como é o caso deste trabalho, cujas bases teóricas encontraram sustentação em pesquisadores da Educação, como é o caso de Luckesi (2005a, 2005b, 2014), Hadji (2001), Fernandes (2006), entre outros. Contudo, procurei entender e apresentar os posicionamentos de linguistas aplicados que relacionam o tema avaliação aos problemas de linguagem, especialmente de ensino e aprendizagem de línguas.

Dentre eles, cito Souza, Racilan e Martins (2012, p. 191) que foram buscar o sentido de avaliação na origem da palavra inglesa assessment, que vem do latim assedere, que quer dizer "sentar-se junto". Esse sentido, de sentar-se junto, de coparticipar do processo de aprendizagem, é que acredito ser a essência da avaliação da aprendizagem.

No inglês tem-se dois elementos lexicais distintos para designar avaliação, assessment e evaluation, que querem dizer respectivamente: fornecer feedback sobre conhecimentos, habilidades, atitudes e produtos de trabalho com a finalidade de elevar a desempenhos futuros e resultados de aprendizagem; e determinar o nível de qualidade de um desempenho ou resultado e permitir a tomada de decisões com base no nível de qualidade comprovada (BAEHR, s.d.). A autora citada afirma que embora haja dois termos para designar as ações, ainda há muita confusão conceitual e acaba-se praticando um único processo de avaliar, embora os dois processos sejam complementares e necessários à educação. 


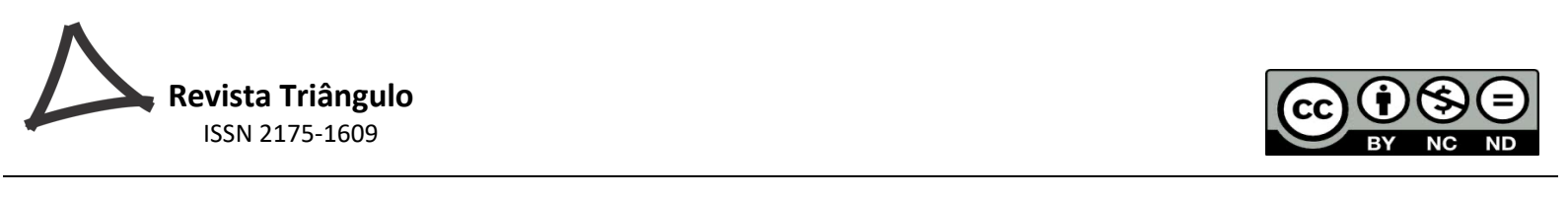

E é essa perspectiva de complementaridade da avaliação que deveria guiar o trabalho pedagógico na escola. Com a intenção de promover a aprendizagem, é preciso refletir, planejar, estabelecer objetivos, criar critérios de avaliação, sempre subordinados a finalidades e objetivos previamente estabelecidos para a prática educativa (DEMO, 1999). A avaliação é uma prática pedagógica contínua, que não se encerra no momento que antecede ou sucede uma determinada unidade de ensino. Ação pedagógica e avaliação são dois processos imbricados e, por isso, não devem ser separados, devem ocorrer continuamente no dia a dia escolar.

No dia a dia escolar mediante as transformações que as tecnologias viabilizam no mundo, outras modalidades de educação e de avaliação surgem no cenário educacional. Em busca da democratização do ensino, a Educação a Distância $(\mathrm{EaD})$ vem crescendo no Brasil e em todo mundo. Esse fato está em consonância com as transformações pelas quais o mundo do trabalho, da cultura e das relações sociais passam, ou seja, o acirramento do processo de globalização da economia e o desenvolvimento e expansão das tecnologias da informação e comunicação (TICs).

A EaD não é uma novidade trazida pelas novas TICs, como relatado por Moore e kearsley (2007, p. 25). Essa modalidade de ensino remonta ao começo dos anos de 1880, em sua Primeira Geração, e passa por desenvolvimentos desde então até chegar ao modelo mediado pelas interações via internet, que seria a Quinta Geração da EaD, que integra em sua interface texto, áudio e vídeo apresentando métodos construtivistas e colaborativos de aprendizagem (MOORE; KEARSLEY, 2007).

A expansão da EaD nos últimos anos no Brasil vem justificada institucionalmente pela necessidade de:

acesso crescente a oportunidades de aprendizado e treinamento; proporcionar oportunidades para atualizar aptidões; melhorar a redução de custos dos recursos educacionais; apoiar a qualidade das estruturas educacionais existentes; melhorar a capacitação do sistema educacional; nivelar desigualdades entre grupos etários; direcionar campanhas educacionais para públicos-alvo específicos; aumentar aptidões para a educação em novas áreas de conhecimento; oferecer uma combinação de 


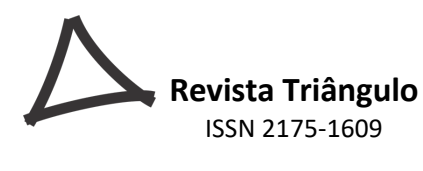

educação com trabalho e vida familiar; agregar uma dimensão internacional à experiência educacional. (MOORE; KEARSLEY, 2007, p.8).

E com isso, a abertura de cursos a distância cresceu sobremaneira, especialmente a partir de 2005, com a adesão das universidades públicas brasileiras na oferta de cursos e geração de ambientes virtuais de aprendizagem (AVAs).

Portanto, uma nova modalidade de ensino, mediada por tecnologias digitais potencializadas pela Internet, vem se desenvolvendo e trazendo novos desafios a todos envolvidos no sistema de ensino, visto que não se trata de transpor uma modalidade para outra, devido à mudança de contexto, ou seja, do presencial para o virtual. Trata-se de uma nova abordagem de ensino e, por isso, novas metodologias e novas formas de avaliação são necessárias.

Segundo Silva (2006), a sala de aula em ambiente on-line pode propiciar "liberdade de autoria, multiplicidade de acessos e de conexões, diálogo, troca de informações e de opiniões, participação, invenção e autoria colaborativa", que são "princípios essenciais à educação cidadã" (SILVA, 2006, p. 27) e fundamentos da avaliação mediadora, terminologia que Silva busca em Hoffmann (2004).

Hoffmann (2004) sintetiza a avaliação mediadora como

um complexo de processos educativos (que se desenvolvem a partir da análise das hipóteses formuladas pelo educando, de suas ações e manifestações) visando essencialmente ao entendimento. Tais processos mediadores objetivariam encorajar e orientar os alunos à produção de um saber qualitativamente superior, pelo aprofundamento às questões propostas, pela oportunização (sic) de novas vivências, leituras ou quaisquer procedimentos enriquecedores ao tema em estudo (HOFFMANN, 2004, p. 61).

Esse modelo de avaliação está em consonância com o que já apresentei anteriormente, defendido por Hadji (2001), Luckesi (2005a, 2005b, 2014) e Fernandes (2006). 


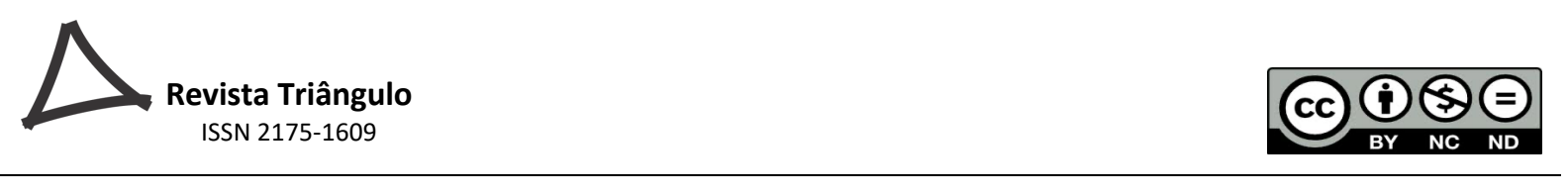

Potencialmente, a sala de aula on-line pode proporcionar experiências de maior autonomia e interação. Mas, para que isso aconteça, a mentalidade de professores e alunos deve ser mudada. A centralidade na transmissão de informações, na memorização, e retenção de conhecimento deve ser descartada. Silva (2006) adverte que há a necessidade de mudança devido à mudança sociotécnica dessa nova sala de aula, que requer percepção crítica e atitude comunicacional diferenciada. De acordo com esse autor, o professor deve disponibilizar aos alunos

a participação na construção do conhecimento e da própria comunicação, entendida como colaboração da emissão e da recepção; diferentemente de transmitir para o receptor massificado, o professor aprende com a dinâmica das tecnologias digitais e com a conectividade online, e libera ao aprendiz a comunicação personalizada, operativa e colaborativa (SILVA, 2006, p. 29).

A interação é a palavra de ordem nessa nova configuração sociotécnica, ou pelo menos deveria ser, visto que muitas vezes o ambiente on-line é subutilizado, tornando-se lugar de transmissão e recepção passiva, assim como na educação tradicional. Nesse novo modelo comunicacional e educacional devemos estar preparados, como professores, para abrir mão de nossa "hegemonia da transmissão e da avaliação fechada", nos dizeres de Silva (2006, p. 31), e estarmos abertos ao diálogo, à negociação, à co-criação, à participação, à colaboração. Silva complementa afirmando que "no ambiente de aprendizagem on-line (mas não só nele) precisamos propor conteúdos de aprendizagem como obra aberta na qual a imersão, a navegação, a exploração e a polifonia possam fluir na lógica da completação (...) todos os participantes poderão contribuir com a dinâmica conectiva e colaborativa" (SILVA, 2006, p. $33)$.

Para o desenvolvimento da aprendizagem e avaliação on-line de forma interativa são necessárias interfaces e ferramentas adequadas, que sejam exploradas de forma proficiente por professores, webdesigners e alunos. De nada adianta criar salas de aula on-line, se estas servirem apenas como repositório de textos, em que não haja ferramentas de interação que 


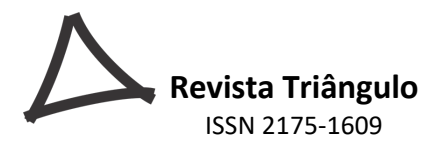

ISSN 2175-1609

permitam o diálogo e com instrumentos avaliativos acríticos que não mobilizem as múltiplas “inteligências" (GARDNER,1995) dos alunos. Trocar o quadro pelo computador simplesmente não mudará nada na educação. O que irá mudar a educação para que esteja alinhada às demandas de nosso tempo é o desenvolvimento de uma postura problematizadora, dialógica, cooperativa entre professores e alunos.

A avaliação, assim como todo o processo educativo, é um sistema complexo, pois é resultado da interação de vários agentes, como professores, alunos, familiares, administradores, Ministério da Educação; e ainda de pressupostos epistemológicos, éticos, técnicos, metodológicos que subjazem às concepções de avaliação. Tudo isso subordinado a diferenças e subjetividades socioculturais, que muitas vezes não são respeitadas, e, por isso, para entender a avaliação, não se pode não levar em conta todos esses aspectos, mesmo que se focalize determinado elemento para a compreensão mais imediata, os outros agentes do sistema não podem ser desconsiderados.

Portanto, falar de avaliação é tocar numa ferida aberta da educação, mas acredito que por meio dela poderíamos intervir nas chagas levando à cura de muitos males.

\section{MÉTODOS}

Este texto trata-se de um relato de minha experiência como professora avaliadora da aprendizagem de meus alunos. Começo a discussão fazendo um percurso histórico da avaliação. Posteriormente, discorro sobre as concepções formativas e emancipatórias de avaliação. Em seguida, analiso a questão da avaliação em ambiente on-line. Relaciono na discussão o início de minha prática avaliativa como professora, minha prática sob esses constructos da avaliação formativa e minha incursão no universo digital. Por último, teço algumas considerações finais.

\section{RESULTADOS E DISCUSSÃO}

Minha postura inicial, logo que adentrei a sala de aula, estava fundada em minhas crenças sobre o que seriam os processos de ensinar, aprender e avaliar. E principalmente nas experiências que vivenciei como aluna no ensino básico e na faculdade. Queria espelhar meus 


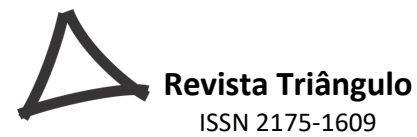

professores, aqueles que eram considerados os melhores, que davam provas difíceis, que eram irredutíveis quanto ao resultado final. Estes foram meus modelos, dada minha insegurança inicial frente a todo o processo educativo, imitava meus professores e suas práticas avaliativas. Não ousaria pensar em criticar esses modelos, visto que eles tinham dado tão certo comigo.

Sabemos que a avaliação, assim como os processos de ensino e aprendizagem, reflete a postura teórico-metodológica assumida pelo professor de forma crítica ou inconsciente, e traduz suas crenças sobre o que ele concebe sobre o que seja ensinar, aprender e avaliar. Essas concepções são muito importantes, pois elas influenciarão todo o processo educativo, levando a ações construtivas e emancipatórias ou reprodutivas e alienantes. O processo avaliativo tem relação direta com a significação que o professor construiu sobre avaliação e que, em decorrência disso, a formação de uma concepção de avaliação como instrumento de comunicação que facilita a construção do conhecimento, depende de uma coerente formação inicial e continuada dos mediadores do processo educativo (NETO; AQUINO, 2010).

Como mencionei anteriormente, minhas experiências anteriores de avaliação subsidiaram minhas práticas avaliativas iniciais como docente, visto que, em minha formação inicial, não havia tido acesso a referenciais teóricos sobre a avaliação que pudessem embasar minha reflexão sobre essa prática pedagógica. O tema avaliação era tocado apenas tangencialmente nas disciplinas de prática de ensino e, mesmo assim, sem o menor aprofundamento teórico e metodológico. Devido à essa lacuna em minha formação, foi em sala de aula que senti a necessidade de entender melhor essa atividade, visto que passei a observar que os instrumentos avaliativos e a forma como conduzia o processo de ensino não estavam gerando a aprendizagem satisfatória em todos os alunos.

As práticas avaliativas às quais recorria eram as atestadas pelos bancos de questões disponibilizados pelos sistemas de ensino nos quais trabalhei, na "certeza" de que, os testes desenvolvidos e aprovados por professores experientes e também as questões trazidas nos livros didáticos, seriam uma forma objetiva e segura de analisar a aprendizagem de meus alunos. Acreditava que provas pontuais ao final de cada unidade de ensino seriam suficientes para aferir o conhecimento dos alunos acerca da matéria. $\mathrm{O}$ instrumento prova seria o que mais conseguiria 


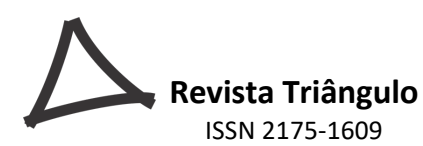

ISSN 2175-1609

identificar o que o aluno sabia. Além desse instrumento, os trabalhos em grupo ou individuais pautados nos preconizados pelo livro didático ou nas apostilas dos sistemas de ensino eram as alternativas avaliativas de que me valia.

Utilizava esses recursos porque ainda não possuía autoconfiança suficiente para elaborar meus próprios instrumentos, achando que os testes endossados por editoras renomadas teriam a validade necessária à avaliação, desmerecendo o conhecimento construído por mim em relação ao contexto de aprendizagem, aos meus alunos e às minhas práticas pedagógicas.

Nunca usei a avaliação como arma, sempre tive a consciência de que não poderia usar da prova como instrumento de poder, mas quantas vezes não retomei o que não foi assimilado, passando o conteúdo para frente sem a preocupação em ajudar aquele(s) aluno(s) que não conseguiu compreender, não cumprindo assim minha função de educadora. Apenas medindo e classificando meus alunos sob critérios pouco claros e sem abordagens epistemológicas do que seria avaliar assumidas criticamente.

Em minha prática pedagógica inicial, como relatei anteriormente, me sentia extremamente insegura no ato de avaliar e, por isso, me valia de recursos como os do livro didático ou dos bancos de questões para elaboração de provas. Esse fato ocorria também devido à falta de embasamento teórico sobre avaliação, que foi ausente em minha formação inicial. E mesmo não conhecendo os preceitos da avaliação formativa, já me sentia incomodada com as práticas avaliativas desenvolvidas por mim e ratificadas nas escolas as quais trabalhei. E por isso, passei a investigar sobre o tema avaliação para tentar mudar minha postura como educadora.

Para esse processo de aprender contínuo, de mudança, encontrei fundamentos em Paulo Freire, que deve ser referência fundamental para todo professor. Em seu texto Educação e Mudança (1979), Freire afirma que o compromisso verdadeiro do profissional está ligado à solidariedade como gesto amoroso, não interessado e assistencialista. O mestre fala do profissional da educação como o homem que deve comprometer-se por si mesmo e que, por apropriar-se do patrimônio cultural da humanidade, a ela deve servir responsavelmente. Para isso, o profissional deve ampliar seu conhecimento sobre o próprio homem e seu contexto de 


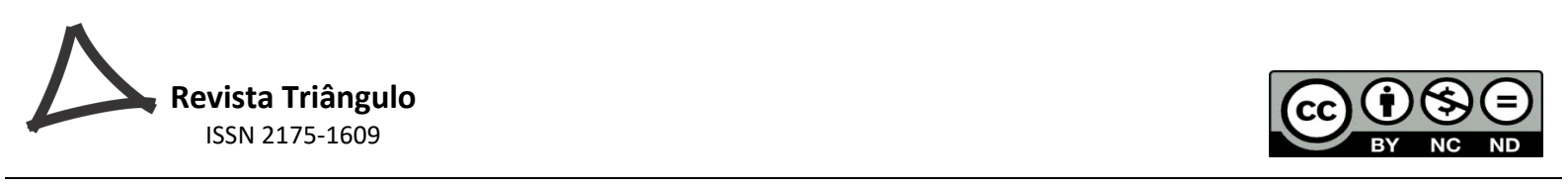

forma crítica. Encontrei nessas palavras um referencial para guiar-me no meu compromisso como educadora, buscando entender meu contexto de atuação.

A princípio, como toda mudança, foi difícil assimilar que a avaliação deveria ser uma prática diária, de retomadas, de cooperação e observação constantes, o que era dificultado muitas vezes por questões relacionadas ao contexto escolar, como cumprimento de prazos e conteúdos, de burocracias, notas; além de questões interpessoais, de indisciplina, de sobrecarga de trabalho, e demais fatores envolvidos no sistema escolar. Todos esses fatores interferem sobremaneira no trabalho cotidiano do professor, especialmente no que tange à avaliação formativa, pois o feedback, a comunicação de resultados, a intervenção no processo de aprendizagem devem ser imediatos ou o mais breve possível, o que as vezes pode não acontecer, devido aos fatores mencionados. Fernandes (2006) discorre sobre a relevância do feedback do professor para reordenar o processo de ensino após a diagnose de uma verificação da aprendizagem do aluno. E a impossibilidade de reordenação do processo pode gerar frustração ao professor, e foi justamente o que senti muitas vezes. Em turmas muito numerosas era muito difícil dar feedback mais pontual nas produções dos alunos.

A solução que encontrei para esse entrave foi dar feedback coletivo e compartilhar com meus alunos a responsabilidade de avaliar suas próprias produções textuais, sua evolução. A autoavaliação, que Fernandes (2006) denomina de autorregulação da aprendizagem, é o monitoramento pelo próprio aluno de sua aprendizagem. $\mathrm{O}$ autor menciona sobre a importância da criação de instrumentos avaliativos inteligentes que mobilizem conhecimentos contextualizados e alinhados com os conteúdos de ensino trabalhados, que tenham propósito pedagógico definido e que após a avaliação sejam retomados os conteúdos que não foram aprendidos.

Um instrumento que achei importante para essa prática autoavaliativa, que de acordo com Hadji (2001, p.102-103) visa desenvolver atividades de cunho metacognitivo, favorecendo a tomada de consciência por parte dos estudantes acerca dos diferentes aspectos e momentos 


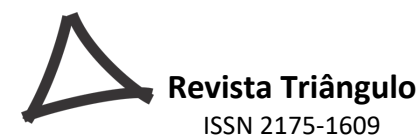

ISSN 2175-1609

das atividades cognitivas que fazem parte do seu processo de aprendizagem, foi o diário reflexivo. Segundo Miranda e Felice (2012, p. 130), o “diário reflexivo é aqui entendido como a produção escrita a partir da reflexão feita pelos alunos, levando em consideração o decorrer das aulas, suas ações e reações diante do conteúdo ensinado". Usei dessa metodologia em turmas de formação de professores e de ensino médio e foi bem interessante. Pedia que os alunos registrassem suas impressões, o conhecimento construído a cada aula, com o intuito de que refletissem sobre sua aprendizagem e, ao mesmo tempo, desenvolvessem a habilidade discursiva escrita. Esse tipo de prática avaliativa, segundo André e Pontin (2010), permite uma dupla retroalimentação, isto é, indica ao aluno seus ganhos, sucessos, dificuldades a respeito das distintas etapas pelas quais passa durante a aprendizagem e ao mesmo tempo permite a construção/reconstrução do conhecimento.

Periodicamente, recolhia os diários para acompanhar o desenvolvimento dos alunos, pedia a eles que lessem suas reflexões para toda turma ou ainda que um colega fosse responsável pela análise do diário. Essa última prática pode ser considerada uma avaliação entre pares, conhecida como coavaliação, que é um momento em que os alunos auxiliam-se mutuamente, observando o trabalho de cada um, verificando inadequações e apontando uma possível solução. Para o desenvolvimento deste tipo de avaliação, é necessário que as regras sejam estabelecidas, como a de que o erro deve ser visto como algo natural ao processo de aprendizagem, não como fator negativo. Com essa atividade, os alunos têm a oportunidade de se colocarem "em situações de confronto, de troca, de interação, de decisão, que os forcem a explicar, a justificar, a argumentar, expor ideias, dar ou receber informações para tomar decisões, planear ou dividir o trabalho, obter recursos" (PERRENOUD, 1999, p. 99).

A partir do viés da avaliação formativa, passei a utilizar outros instrumentos como práticas avaliativas além da prova, como dramatizações, debates, jogos, resenhas, confecção de vídeos, projetos, entre outros. O instrumento prova passou a se fazer necessário somente quando era uma exigência institucional, pois passei a acreditar que a variabilidade das práticas 


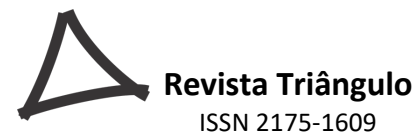

avaliativas é que possibilitariam que meus alunos tivessem mais oportunidades de aprendizagem e de comprovação da mesma.

Quando refiro-me que passei a utilizar outros instrumentos e não a prova, isso não quer dizer que a prova em si seja ruim, é o que se faz com seus resultados que pode mutilar o processo de aprendizagem. Lembrando que o feedback não é a salvação do processo de aprendizagem. A simples presença do feedback não é suficiente para que haja a aprendizagem. É importante construir modelos teóricos de aprendizagem, instrumentos e modelos de ação, pois o feedback é um dos elemento da avaliação formativa, mas não só.

Além de tudo, muitos obstáculos impedem a emergência de uma avaliação com intenção formativa (EVF, sigla em francês), como nos adverte Hadji (2001). Esse autor afirma que existem representações inibidoras, que tornam-se concepções que impedem a construção de conceitos científicos, porque estão arraigadas na mente de administradores escolares, pais, professores e alunos, que acreditam que a avaliação é representada por notas. O professor que quer implementar uma EVF deve mudar essa mentalidade condicionada por fatores de ordem ideológica e social, buscando subsídios em um quadro teórico que dê conta da diversidade do fenômeno da aprendizagem e na interpretação dos dados obtidos na avaliação diagnóstica de seus alunos, compreendendo o "funcionamento" do aluno e dos objetos de ensinar. Outro obstáculo citado por Hadji (2001) é a preguiça e o medo dos professores que não "ousam imaginar remediações". Cabe ao professor a iniciativa de transgredir a tradição e buscar alternativas avaliativas que estejam a serviço da aprendizagem dos alunos. Por isso, acredito na utopia promissora da avaliação, que Hadji (2001) discute, pois foi essa utopia que passou a orientar meu trabalho de professora, no sentido de correlacionar atividade avaliativa e atividade pedagógica. Apesar de nunca ter a certeza de estar fazendo a coisa certa, tenho sempre em mente que meu trabalho é cooperar para a aprendizagem de meu aluno.

Minha experiência com a sala de aula on-line teve início quando, por influência uma de grande uma amiga, criei uma rede social na internet para interagir com meus alunos do ensino 


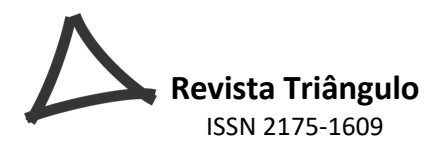

médio. Não se tratava de um curso a distância, mas sim uma sala de aula virtual como extensão da sala de aula convencional no ensino regular, que foi criada devido à pouca carga horária destinada à disciplina que ministrava naquela época, Literatura Brasileira. Minha intenção com a criação da rede social era promover uma maior interação entre os alunos, veicular as produções desenvolvidas na disciplina, ser um espaço no qual pudéssemos aprofundar os conhecimentos em Literatura Brasileira. Como plataforma on-line, utilizei a rede NING, que a princípio era uma rede gratuita, que por ser um software proprietário, passou a cobrar pelo seu uso em dólar. Essa cobrança, embora tenha pago por mais de um ano, inviabilizou a continuidade de sua utilização.

Esse ambiente on-line disponibiliza diversas ferramentas, como blog, wiki, fórum de discussão, e era possível postar textos, imagens, vídeos, músicas, e outras semioses. Era um ambiente multimodal, que possibilita o desenvolvimento dos multiletramentos dos alunos. Essa experiência com a rede social NING foi muito proveitosa e nela pude desenvolver instrumentos avaliativos diferenciados dos convencionais, com os quais meus alunos puderam colocar a imaginação e criatividade em ação, como o desenvolvimento de vídeos com releituras de obras literárias, documentários sobre a vida de autores, criação e veiculação de poemas multimodais, desenvolvimento de fóruns de discussão sobre a leitura de obras literárias, veiculação de resenhas sobre obras literárias, apresentação de textos literários e artigos de opinião produzidos pelos alunos, criação de mapas conceituais sobre obras literárias, podcasts sobre estilos de época, entre outras atividades.

Depois dessa experiência com a rede NING, passei a utilizar com meus alunos a rede mais acessada no mundo naquela época, o Facebook. E desde então, utilizei esse fenômeno social para interagir com os alunos de forma mais rápida e eficiente, visto que a grande maioria dos alunos possuia conta nessa rede e a acessa diariamente.

Todas essas experiências e práticas avaliativas foram negociadas com os alunos, e várias delas foram propostas por eles como a criação dos vídeos, dos documentários, dos fóruns de discussão. As atividades eram avaliadas por mim e pelos próprios alunos, que atribuíam um conceito previamente estabelecido. 


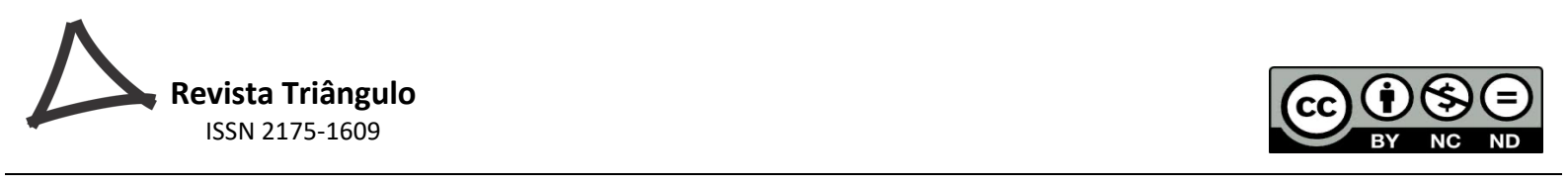

Essa primeira incursão pela sala de aula on-line foi muito enriquecedora para mim como profissional e como pessoa, pois tive a oportunidade de conviver mais de perto com meus alunos apesar da virtualidade. Depois dessa experiência, nunca mais abri mão dos recursos da internet e web para o desenvolvimento de minhas aulas.

Na universidade, conheci o ambiente Moodle, que é o ambiente virtual de aprendizagem institucional utilizado pela maioria das universidades brasileiras. Nas disciplinas que ministrei em curso presencial em uma universidade pública, criei salas de aula virtuais para ampliar a comunicação com os alunos, o que rendeu bons resultados. Nessas salas de aula on-line, pude desenvolver também atividades avaliativas com intenção formativa variadas, como fóruns de discussão sobre leituras teóricas e temas específicos das disciplinas em questão. Nesses fóruns, os alunos desenvolviam argumentação relativa ao tema proposto e ao longo do debate eles se auto e co-avaliavam, visto que no fórum os alunos têm a oportunidade de embate, de críticas, de retomadas, de confronto, às vezes. Minha participação era de mediadora e fomentadora da discussão, deixando que os próprios alunos propusessem as questões a serem debatidas e relacionassem os questionamentos com suas experiências de vida e aos contextos que estávamos inseridos.

As experiências até então vivenciadas por mim e narradas neste texto tinham sido com a criação de salas de aula virtuais como extensão das salas de aula presenciais em cursos regulares de diferentes níveis de ensino. No entanto, tive a oportunidade de trabalhar com o ensino a distância em cursos de formação de professores posteriormente. Embora nunca tenha trabalhado com educação a distância até então, já tinha feito uma especialização a distância na UFMG, que tratava justamente do uso das tecnologias no ensino de línguas, o que serviu de referencial para minha atuação como professora da educação a distância. Nessa especialização tive a oportunidade de entender essa modalidade de ensino e estudar os referenciais da educação a distância no Brasil, assim como as potencialidades das ferramentas digitais da internet e da 


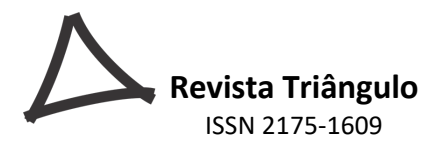

web para o ensino de línguas. Essa especialização foi fundamental em minha formação e graças a ela mudei o rumo dessa formação, de lexicógrafa à linguista aplicada.

No curso de formação de professores a distância no qual atuei, tinha as funções de professora conteudista e formadora. Na terminologia do ensino a distância, o professor conteudista é aquele que planeja o curso, desenha todo o material de apoio e o ambiente virtual de aprendizagem, e o formador é aquele que acompanha, juntamente com o tutor, o desenvolvimento do curso junto aos alunos sanando os problemas que surgem no decorrer do curso. Foi um desafio planejar os cursos, visto que temos que desenhar todo o material, pensar nas atividades avaliativas sem conhecer o perfil dos alunos, sem ter a menor ideia de como eles são. Acredito que esse seja um ponto negativo no planejamento de cursos a distância, o material é previamente elaborado, sem o reconhecimento dos participantes, e muito menos a sua participação na elaboração. No entanto, como professora conteudista e formadora tenho autonomia de mudar e reorganizar o curso para que atenda às necessidades dos alunos. Acredito que essa possibilidade é o que propicia a emergência de aprendizagem contextualizada e formadora.

Embora tenha que elaborar previamente as atividades avaliativas sem ter interagido com meus alunos, tento pensar em atividades que possibilitam a interação durante o curso, como os fóruns de discussão, nos quais o aluno tem a possibilidade de expressar sua identidade contribuindo para a construção coletiva do conhecimento acerca do tema discutido, ao mesmo tempo negociando e respeitando a opinião dos colegas. O fórum de discussão é um bom exercício de cidadania, se encaminhado de forma a propiciar o engajamento, e não apenas o cumprimento de tarefa. É uma atividade avaliativa formativa, pois possibilita que o aluno reveja seus posicionamentos, reflita, discuta com argumentos advindos de sua experiência e pesquisa e, a partir do confronto com as ideias dos colegas e professor, emerja um sujeito mais consciente, mais crítico ou com mais dúvidas, o que irá gerar mais debate. 


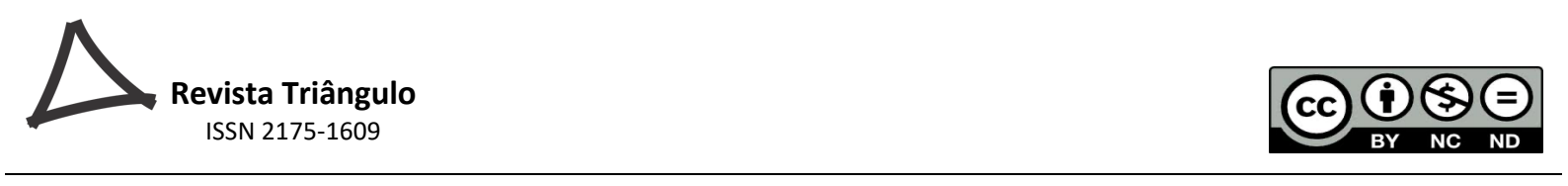

Outra atividade avaliativa formativa, que já mencionei anteriormente, e que promove o desenvolvimento da criticidade do aluno e sua autoavaliação é o diário reflexivo. No ambiente virtual de aprendizagem utilizado no curso a distância mencionado, há a ferramenta diário de bordo, que pode servir como diário reflexivo, no qual o aluno registra suas impressões acerca do tema trabalhado, expõe suas ideias e revê seus posicionamentos acerca do ensino de línguas e do trabalho do professor.

O ambiente Moodle propicia diversas ferramentas que podem ser utilizadas como instrumentos avaliativos. Além do fórum de discussão e do diário de bordo, o professor pode criar tarefas, wikis, questionários, lições, glossários, dentre outras atividades. Acredito que o que importa é a forma como o professor elabora a avaliação, visto que um instrumento tradicional, como a prova, pode ser uma avaliação formativa a partir do momento que o professor elabora questões contextualizadas e que haja feedback dos resultados e retomadas do conteúdo, se necessário. Por outro lado, um instrumento a princípio interativo e formativo, como o fórum de discussão, pode se tornar uma atividade avaliativa excludente se apenas o posicionamento do professor prevalecer e servir apenas como cumprimento de um cronograma ou tarefa estipulada.

Assim, cabe ao professor orientar o processo de aprendizagem e a avaliação, compreendendo que todos nós, professores e alunos, somos seres em construção, como dizia nosso mestre Paulo Freire, e por isso mesmo precisamos sempre estar abertos à mudança.

\section{CONSIDERAÇÕES FINAIS}

Neste texto, minha intenção foi discutir a questão da avaliação como elemento central na aprendizagem e evidenciar que as práticas avaliativas estão alicerçadas nas concepções que temos do que seja ensinar, aprender e avaliar. E que essas concepções não são fixas, visto que estamos todos, professores e alunos, sempre aprendendo.

Relatei minhas experiências como avaliadora da aprendizagem de meus alunos ressaltando que a avaliação é sempre uma possibilidade utópica, como afirma Hadji (2001), que 
a avaliação formativa é a relação de ajuda que se estabelece entre professor e aluno. Tem que haver uma relação de ajuda mútua entre esses dois agentes, compreendendo que ensinar e aprender é uma via de mão dupla.

A avaliação da aprendizagem é um tema que deve ser sempre discutido e pensado pelos professores, pois pode determinar os rumos da educação. E esse tema em ambiente virtual de aprendizagem carece ainda mais de reflexões, visto que é uma realidade nova, mas que pode significar a mudança paradigmática dos rumos da educação como um todo.

Minha experiência com o universo on-line está só começando, espero que muitas outras oportunidades surjam e tenho certeza que essa modalidade de ensino a cada dia ampliar-se-á. Os ambientes virtuais de aprendizagem podem significar a mudança tão necessária à educação, pois requer que repensemos os velhos métodos, os preceitos enrijecidos do paradigma racionalista e entendamos de uma vez por todas que a prática educativa, e como parte inseparável dela, a prática avaliativa, é um processo dinâmico, formativo, vivo.

\section{REFERÊNCIAS}

ANDRÉ, M. E. D. A. de; PONTIN, M. M. D. Meta: Avaliação. Rio de Janeiro, v. 2, n. 4, p. 13-30, jan./abr. 2010.

BAEHR, M. Distinctions Between Assessment and Evaluation. Disponível em: http://www.pcrest2.com/institute_resources/PAI/4_1_2.pdf Acesso em: 10 de jan. 2020.

CALDEIRA, A. M. S. Avaliação e processo de ensino e aprendizagem. Presença Pedagógica, Belo Horizonte, v. 3, p. 53-61, set./out. 1997.

DEMO, P. Avaliação qualitativa. 6. ed. Campinas, SP: Autores Associados, 1999.

FERNANDES, D. Para uma teoria da avaliação formativa. Revista Portuguesa de Educação, 2006, 19(2), pp. 21-50. CIEd - Universidade do Minho.

FREIRE, PAULO. Educação e Mudança. Tradução Moacir Gadotti e Lilian Lopes Martin. Rio de Janeiro: Paz e Terra, 1979. Coleção Educação e Comunicação. vol. I.

GARDNER, H. Inteligências Múltiplas: a Teoria na Prática. Porto Alegre: Artes Médicas, 1995. 
GATTI, B. A. O Professor e a avaliação em sala de aula. Estudos em Avaliação Educacional, n. 27, p. 97-113, jan./jun. 2003.

GRILLO, M. C.; LIMA, V. M. do R. Especificidades da avaliação que convém conhecer. In: Por que falar ainda em avaliação? [recurso eletrônico] /organizadoras, Marlene Correro Grillo, Rosana Maria Gessinger; Ana Lúcia Souza de Freitas ... [et al.]. - Porto Alegre: EDIPUCRS, 2010.

HADJI, Charles. Avaliação desmistificada. Trad. Patrícia Ramos. Porto Alegre: Artmed, 2001.

HOFFMANN, J. Avaliar para promover: as setas do caminho. Porto Alegre: Mediação, 2004.

LIBÂNEO, J. C. Didática. 2. ed. São Paulo: Cortez, 1994.

LUCKESI, C. C. Avaliação da aprendizagem escolar. 4 ed. São Paulo: Cortez, 1996.

LUCKESI, C. C.O que é mesmo o ato de avaliar a aprendizagem? Pátio. Porto alegre: ARTMED. Ano 3, n. 12 fev./abr. 2000.

LUCKESI, C. C. Entrevista à revista nova escola sobre avaliação da aprendizagem (Esta entrevista subsidiou matéria que saiu na Revista Nova Escola de novembro de 2001). Disponível em: www.luckesi.com.br Acesso em 10 de jan. de 2015.

LUCKESI, C. C. Avaliação da aprendizagem... mais uma vez. Artigo publicado na Revista ABC EDUCATIO n. 46, junho de 2005a. Disponível em: www.luckesi.com.br Acesso em: 10 de jan. de 2015.

LUCKESI, C. C. Avaliação da aprendizagem escolar. 17 ed. São Paulo: Cortez, 2005b.

LUCKESI, C. C. A base ética da avaliação da aprendizagem na escola. sd. Disponível em: www.luckesi.com.br Acesso em: 19 de jan. 2020.

LUCKESI, C. C. Sobre notas escolares: distorções e possibilidades. São Paulo: Cortez, 2014.

MIRANDA, J. I. F.; FELICE, M. I. V. O Diário Reflexivo como Instrumento da Avaliação Formativa. Revista Intercâmbio, v. XXVI: 129-153, 2012. São Paulo: LAEL/PUCSP. ISSN 2237-759x

MOITA LOPES, L. P. (Org.) Por uma Linguística Aplicada (In)disciplinar. São Paulo: Parábola Editorial, 2006. 279 p.

MOORE, M.; KEARSLEY, G. Educação a distância: uma visão integrada. Trad. Roberto Galman. São Paulo: Thomson Learning, 2007.

NETO, A. L. G. C.; AQUINO, J. de L. F. A avaliação da aprendizagem como um ato amoroso: o que o professor pratica? Educação em Revista. Belo Horizonte. v.25. n.02. p.223-240. ago. 2010. 
PERRENOUD, P. Avaliação da Excelência à Regulação das Aprendizagens. Entre Duas Lógicas. Porto Alegre: ARTMED, 1999. (Original publicado em 1980)

REMIÃO, J. E. Avaliação: exclusão ou inclusão. In: MELO, Marcos Muniz (Org.). Avaliação na educação. Pinhais: Melo, 2007.

SANT'ANNA, I. M. Por que avaliar?: Como avaliar?: critérios e instrumentos.3. ed. Petrópolis, RJ: Vozes, 1995.

SILVA, M. O fundamento comunicacional da avaliação da aprendizagem na sala de aula online. In: SILVA, M.; SANTOS, E. (org.). Avaliação da aprendizagem em educação on-line. São Paulo: Edições Loyola, 2006.

SOUZA, V. V. S.; RACILAN, M.; MARTINS, A. C. S. O uso de tecnologias digitais na avaliação da aprendizagem. In: BRAGA, J, F. (org). Integrando tecnologias na aula de Inglês nos anos finais do Ensino Fundamental. São Paulo: Editora SM, 2012.

TYLER, W. R. Como se pode avaliar a eficácia de experiências de aprendizagem? In: Princípios Básicos de Currículo e Ensino. 6 ed. Porto Alegre: Globo, 1979. 